\title{
Características Qualitativas da Informação Contábil: Um Estudo da Percepção dos Concludentes do Curso de Ciências Contábeis da $\mathrm{UFCG}^{1}$
}

\section{Qualitative Characteristics of Accounting Information: A Study of the Perception of Conclusive Course of Accounting Sciences from UFCG}

\section{Características Cualitativas de la Información Contable: Un Estudio de la Percepción de los Concluyente de Curso de Contabilidad del UFCG}

\author{
Francisco Daênnio Casimiro de Oliveira \\ Graduado em Ciências Contábeis idade Acadêmica de \\ Ciências Contábeis - UFCG \\ Rua, Sinfrônio Nazaré, 38, Centro, Sousa, PB, CEP: \\ 58.800-240. \\ e-mail: fabianoferreirabatista@yahoo.com.br
}

\section{Lúcia Silva Albuquerque}

Mestra e Professora da Universidade Federal de Campina Grande e da Universidade Estadual da Paraíba Rua, Sinfrônio Nazaré, 38, Centro, Sousa, PB CEP: $58.800-240$.

e-mail: $\underline{\text { luciasalbuquerque@gmail.com }}$
Fabiano Ferreira Batista

Mestre e Professor Assistente da Unidade Acadêmica de Ciências Contábeis - UFCG Rua, Sinfrônio Nazaré, 38, Centro, Sousa, PB CEP: $58.800-240$. e-mail: fabianoferreirabatista@yahoo.com.br

\author{
Gianinni Martins Pereira \\ Professora da Unidade Acadêmica de Ciências Contábeis \\ UFCG \\ Rua, Sinfrônio Nazaré, 38, Centro, Sousa, PB \\ CEP: 58.800-240. \\ e-mail: gianinni.martins@gmail.com
}

\section{RESUMO}

O objetivo da contabilidade é fornecer aos usuários informações capazes de fundamentar e tornar mais confiável a tomada de decisão. Para tanto, faz-se necessário que tais informações estejam dotadas de características que lhe concedam qualidade. $\mathrm{O}$ presente trabalho objetivou analisar se para os alunos concludentes do curso de ciências contábeis da UFCG campus Sousa, a forma de apresentação das informações contábeis e a presença das características qualitativas nestas, geravam impacto/influência na tomada de decisão, buscou-se ainda avaliar, na percepção dos respondentes o grau de importância de cada característica. A pesquisa foi aplicada junto a 40 concludentes, amostra essa não probabilística e por acessibilidade, através de um questionário onde as questões estavam dispostas de duas formas: primeiramente com a ausência das características induzindo o respondente a tomar uma decisão, e posteriormente com a presença das características, de modo, a avaliar se desta forma haveria alguma

\footnotetext{
${ }^{1}$ Artigo recebido em 06.02.2014. Revisado pelos pares em 14.07.2014 (blind review). Ajustado e Aceito para publicação em 31.07.2014. Recomendado para publicação por José Ribamar Marques de Carvalho (Editor Científico). Publicado em 15.08.2014. Organização responsável UACC/CCJS/UFCG.
} 
mudança na tomada de decisão; havia também uma escala, por meio da qual, era possível atribuir o grau de importância a cada característica. Por meio da análise dos dados, foi possível concluir que a forma de apresentação e a presença das características qualitativas da informação contábil impactam na tomada de decisão, e que os concludentes apresentaram um nível de conhecimento satisfatório a cerca das características qualitativas e no geral julgam estas como importantes ou muito importantes.

Palavras-chave: Informação Contábil. Características qualitativas. Usuários da informação.

\section{ABSTRACT}

The purpose of accounting is to provide information to users able to motivate and to make more reliable decision making. Therefore, it is necessary that such information be provided with features that grant you quality. The present study aimed to examine whether the conclusive students of accounting sciences campus UFCG Sousa, the form of presentation of financial information and the presence of these quality characteristics, generate impact 1 influence in decision making, we sought to further evaluate the respondents perception of the degree of importance of each characteristic. The research was applied along the 40 conclusive, this non-probability sample and accessibility through a questionnaire in which the questions were arranged in two ways: first by the absence of features induce the respondent to make a decision, and later with the presence of characteristics, in order to assess whether this way there would be any change in decision making; was also a scale, whereby it was possible to assign the degree of importance to each characteristic. Through data analysis, it was concluded that the presentation and the presence of the qualitative characteristics of accounting information impact on decision making, and that conclusive showed a satisfactory level of knowledge about the qualitative features and overall judge these as important or very important.

Keywords: Accounting Information. Qualitative characteristics. Information users.

\section{RESUMEN}

El propósito de la contabilidad es proporcionar información a los usuarios capaces de motivar y hacer la toma de decisiones más fiable. Por lo tanto, es necesario que dicha información se proporcionará con las características que le conceda la calidad. El presente estudio tuvo como objetivo examinar si los estudiantes concluyentes de las ciencias de la escuela de contabilidad UFCG Sousa, la forma de presentación de la información financiera y la presencia de estas características de calidad, generan impacto / influencia en la toma de decisiones, hemos tratado de evaluar más a fondo la percepción de los encuestados, el grado de importancia de cada característica. La investigación se aplicó a lo largo del 40 concluyentes, esta muestra no probabilística y la accesibilidad a través de un cuestionario en el que las preguntas se organizaron en dos sentidos: en primer lugar por la ausencia de características inducir al entrevistado a tomar una decisión, y más tarde con la presencia de características, con el fin de evaluar si esta forma no habría ningún cambio en la toma de decisiones; Hubo también una escala, mediante la cual fue posible asignar el grado de importancia de cada característica. A través del análisis de datos, se concluyó que la forma de presentación y la presencia de las características cualitativas de la información contable impacto en la toma de decisiones, y que concluyente mostraron un nivel satisfactorio de conocimientos acerca de las características cualitativas y juez general estos como importante o muy importante.

Palabras clave: la información contable. Características cualitativas. Usuarios de la información.

REUNIR: Revista de Administração, Contabilidade e Sustentabilidade ISSN: 2237-3667, Vol. 4, $\mathrm{n}^{\circ}$ 2, p. 96-113, 2014. 


\section{INTRODUÇÃO}

Nos últimos anos a informação contábil vem sendo objeto de investigação no sentido de minimizar as variações de entendimento, ocasionadas por ruídos de comunicação entre a contabilidade e seus usuários. Esses ruídos acabam atrapalhando o processo comunicacional e comprometendo o feedback, uma vez que de nada adianta o uso das mais avançadas ferramentas de tecnologia se não há a compreensão da informação, menos ainda seu compartilhamento. Logo, percebe-se que essa informação de nada serviria por não ser útil na tomada de decisão.

Dessa forma, para que seja percebido o benefício proporcionado pela informação contábil, faz-se necessário a evidenciação dessas informações como requisito essencial para a plena realização do objetivo principal da contabilidade. Assim, a contabilidade procura traduzir, em seu trabalho final, o máximo de transparência, de compreensão e legibilidade dos dados coletados, para conseguir proporcionar, junto a seus usuários e o sistema contábil, um meio de interação eficaz (DIAS FILHO, 2000).

Ainda conforme Dias e Filho (2000) percebe-se que há a necessidade de admissão da Contabilidade como uma revelação linguística, mesmo que esta seja somente para o universo dos negócios, devido ao seu objeto de estudo e campo de atuação.

Admite-se que o entendimento da informação depende também da capacidade de interpretação do usuário e toda a abordagem ficará intimamente ligada à ideia de que este possui uma experiência suficiente para entender o conteúdo dos demonstrativos contábeis. Tal embasamento encontra apoio no ponto de vista do Financial Accounting Standards Board (FASB), onde, deva existir a utilização de esforços para aumentar o entendimento das informações contábeis, elas "devem ser compreensíveis aos que possuem uma noção razoável dos negócios e das atividades econômicas e se dispunham a estudá-las com certa diligência". O International Accounting Standards Board (IASB) e o Comitê de Pronunciamentos Contábeis (CPC) possuem o mesmo posicionamento.

As dificuldades aqui expostas podem ser consideradas relevantes, tendo em vista que a Estrutura Conceitual Básica da Contabilidade aprovada pelo Instituto Brasileiro dos Contadores (IBRACON), em 1986, previne erros de comunicação e evidenciação decorrentes de problemas de linguagem inadequada e outros motivos pelos quais se pode relatar um menor aproveitamento das informações apresentadas nas demonstrações contábeis.

Mediante evidências de que as informações contábeis e o meio pelo quais as mesmas são apresentadas podem influenciar nas decisões dos usuários, o presente tem como objetivo verificar se a presença das características qualitativas das informações 
contábeis exerce impacto no processo decisório dos concludentes do curso de Ciências Contábeis do Campus Sousa. Aliado a isso será avaliada a percepção dos concludentes acerca do seu conhecimento relacionado às características qualitativas da informação contábil e sua importância no processo de comunicação e qual o grau de importância atribuído pelos concludentes a cada uma das características abordadas na pesquisa.

\section{FUNDAMENTAÇÃO TEÓRICA}

\subsection{Teoria da Comunicação e Informação Contábil}

Informação é o produto obtido do processamento, manipulação e organização de dados, de forma que exerça uma alteração (quantitativa ou qualitativa) no conhecimento de quem a recebe, reduzindo incertezas e sua utilidade pode ser medida pela divergência entre a incerteza dos usuários, antes e após o recebimento das informações (DIAS FILHO, 2000).

Segundo Alves (2003), a informação também pode ser entendida como um conjunto de dados, prontos para uso, úteis e organizados com a ausência de viés. Ela desempenha uma força que segrega e modifica realidades bastante expressivas, pois ao obtê-la na hora oportuna, com clareza e de fonte fidedigna, essa informação pode ser primordial na tomada de decisão.

Dias Filho (2000) destaca que a Contabilidade não consegue alcançar um nível satisfatório de informação para alguns usuários e enfatiza que a Contabilidade, à luz da Teoria da Comunicação, deveria distinguir quais são as necessidades dos usuários, para a partir destas desenvolver o meio de comunicação a ser utilizado.

No entanto, sabe-se que os usuários das informações contábeis são capazes de serem identificados a partir de sua perspectiva sobre a informação, que podem ser usuários internos e externos e que os diversos tipos de usuários da informação contábil apresentam-se diferentes quanto à utilização dessas informações geradas. As informações precisam ser apresentadas de tal forma que cada usuário possa utilizá-las de acordo com suas necessidades, conhecimento prévio ou expectativas (PAIVA, 2009).

Dias Filho (2000) destaca que a Contabilidade não consegue alcançar um nível satisfatório de informação para alguns usuários e enfatiza que Contabilidade, à luz da Teoria da Comunicação, deveria distinguir quais são as necessidades dos usuários, para a partir destas desenvolver o meio de comunicação a ser utilizado.

Iudícibus (2009) aponta duas abordagens dos objetivos da contabilidade. Para uma, a Contabilidade precisaria assistir as necessidades de todos os usuários, por meio de um conjunto simples de informações, para outra, precisaria disponibilizar um banco 
de informações específicas para cada espécie usuário. Na prática, as duas são ineficientes, sabendo que não há a possibilidade de atender a todas as necessidades dos que dela dependem, pois cada um possui seus objetivos e necessidades diferentes, e mesmo que soubesse seria utópico acreditar que todos os usuários seriam capazes de entender.

Para entender a comunicação da informação contábil, é necessário entender primeiramente qual seria a função da Contabilidade, que seria fornecer informações úteis, no momento oportuno para auxilio na tomada de decisão. Para tanto, pode-se dizer que tão importante quanto produzir uma informação correta, é assegurar que ela possa ser compreendida pelo usuário, para que assim seja usada como instrumento de apoio no processo decisório.

Assim, diante da diversidade de usuários, cada com interesses distintos e consequentemente com modelos decisórios diferentes e capacidade de interpretação diferenciada a contabilidade se depara com limitações no sentido de atender as necessidades de informações destes e acaba por determinar um grupo de usuários como principal ao qual tenta satisfazer suas necessidades informacionais. Nesse contexto pode-se identificar diferentes focos (onde possivelmente em um contexto de empresas de pequeno porte será o fisco) e com modelos de evidenciação específico, requerendo para alguns usuários um conhecimento profundo, para que seja possível compreender as informações contábeis fornecidas.

Paralelo ao problema de atendimento das necessidades de todos os usuários, Iudícibus (2009) e Carvalho (1991) concordam que, para que o processo comunicacional aconteça, deve ser levada em consideração a capacidade que os usuários possuem de interpretar as informações, de modo a não torná-las inúteis.

Assim, a Teoria da Comunicação atuaria no aperfeiçoamento da qualidade das informações e que a Teoria Matemática da Comunicação, criada por Shannon, em que a informação é tratada como um redutor de incertezas de acordo com a capacidade de interpretação do receptor e para que isso aconteça é preciso visualizar a contabilidade como um processo de comunicação que necessita de duas dimensões: a dimensão da observação e a dimensão da produção. A primeira dimensão compreende o recebimento de informações, interpretação destas e escolha daquela que deverá ser comunicada. A dimensão da produção engloba a codificação da informação e transmissão desta até o usuário. Nesse processo são necessários como elementos os eventos econômicos, o contador, os demonstrativos contábeis e o usuário das informações (BEDFORD \& BALADOUNI,1962 apud DIAS FILHO, 2000).

Berlo (1997) relata que a comunicação pode ser prejudicada pelo fato do emitente não se expressa de maneira adequada, dizendo algo diferente do que pretendia; o 
receptor compreende a mensagem de modo inapropriado, que não se coaduna com a intenção do emitente; e a mensagem recebida difere da enviada, por ter sido deturpada ou alterada enquanto era transportada. Essas interferências são chamadas de ruídos e apresentam-se inversamente proporcionais à fidelidade, prejudicando o processo comunicacional.

Estes ruídos tem a capacidade de intervir no entendimento dos usuários das informações contábeis, ou até prejudicar a qualidade da informação. Diante os ruídos que se encontram no processo comunicacional contábil, Libonati e Souto Maior (1996), citam aqueles que acontecem com maior frequência: Nomenclatura contábil imprópria (terminologia contábil); Quantidade de informação divulgada; Capacidade de entendimento do usuário; Expressões e termos em outros idiomas.

\subsection{Características qualitativas da Informação Contábil}

Para que as informações fornecidas pela contabilidade atendam as necessidades dos usuários e sejam utilizadas por estes nas suas decisões, são necessários requisitos básicos para que se alcance um nível de satisfação.

Mediante a Estrutura Conceitual anterior no Brasil aprovada pelo CPC 00 (2008) com base na Estrutura Conceitual do IASB (2001), estabelecia que as características qualitativas da informação contábil, que foram definidas como atributos, que tornam as demonstrações contábeis úteis, classificavam-se em quatro principais: Compreensibilidade, Relevância, Comparabilidade e Confiabilidade. Neste mesmo contexto, definia ainda que cinco atributos faziam-se necessários para que a informação pudesse ser confiável, seriam estes: Representação Adequada, Primazia da Essência sobre a Forma, Neutralidade, Integridade e Prudência.

O CPC 00 passou por algumas mudanças em sua estrutura, onde as características qualitativas da informação contábil-financeira passaram a ser divididas em:

(a) características qualitativas fundamentais (fundamental qualitative characteristics- relevância e representação fidedigna), as mais críticas; e

(b) características qualitativas de melhoria (enhancing qualitative characteristics - comparabilidade, verificabilidade, tempestividade e compreensibilidade), menos críticas, mas ainda assim altamente desejáveis.

Dentre as modificações percebidas tem-se que a característica qualitativa Confiabilidade foi reclassificada de Representação fidedigna; a Essência sobre a Forma 
foi retirada da condição de componente separado da Representação Fidedigna, uma vez que foram consideradas uma redundância; a Prudência (ou conservadorismo) também precisou ser retirada por ser inconsistente com a neutralidade.

A classificação da Relevância e Representação Fidedigna como características qualitativas fundamentais parece ser indiscutível uma vez que a informação necessita ser relevante e simultaneamente desempenhar com fidedignidade a realidade apresentada para que possa ser útil. Uma representação fidedigna de um acontecimento irrelevante é tão inútil quanto uma representação não fidedigna de um acontecimento relevante, não poderá servir de auxilio ao usuário em uma boa tomada de decisão.

Para tornar as características qualitativas fundamentais mais eficientes e efetivas, são necessárias três etapas: Primeiro, reconhecer o fenômeno econômico que tenha o potencial de ser útil para os usuários da informação. Segundo, identificar o tipo de informação sobre o fenômeno que teria maior relevância se estivesse acessível e que poderia ser desempenhado com fidedignidade. Terceiro, avaliar se a informação está acessível e pode ser desempenhada com fidedignidade.

Já no que diz respeito as características qualitativas de melhoria a Comparabilidade, Verificabilidade, Tempestividade e Compreensibilidade são características que favorecem o benefício gerado pela informação que é relevante e que é representada com fidedignidade, ajudando a identificar qual de duas alternativas que sejam declaradas semelhantes na medida de relevância e fidedignidade de representação deve ser utilizada para representar um fenômeno, necessitando serem maximizadas no maior alcance possível, mas mesmo que sejam individualmente ou em grupo, elas tem a capacidade de tornar a informação útil se esta for irrelevante ou não for representação fidedigna (CPC, 2011).

\section{MÉTODO DE PESQUISA}

A pesquisa teve como universo 75 alunos concludentes do curso de Ciências Contábeis do ano de 2013 da UFCG - Campus Sousa - dos quais, por acessibilidade, trabalhou-se com uma amostra não probabilística de 40 alunos.

Definida a amostra de investigação utilizou-se de um instrumento de coletas na forma de questionário composto de 5 blocos. O primeiro bloco contemplava questões que evidenciam os dados dos respondentes; o segundo referia-se a instruções de preenchimento; o terceiro bloco de questões continha situações que requeriam do respondente um posicionamento, dentre dois preestabelecidos; o quarto bloco apresentava as mesmas situações do terceiro bloco, mas com a inclusão de uma informação munida de determinada característica qualitativa, em que se requeria o 
posicionamento do respondente dentre dois preestabelecidos e idênticos aqueles apresentados no bloco 3, de modo que, permitisse avaliar se a inclusão daquela informação resultaria em mudança de posicionamento por parte do respondente. $\mathrm{O}$ quinto e último bloco buscava saber do respondente qual o grau de importância que ele atribuía a cada característica qualitativa da informação elencada, por meio de uma escala de likert que variava de "sem importância" a "muito importante".

Após a coleta, as informações extraídas foram organizadas e tabuladas com o auxilio do Microsoft Excel 2007.

\section{ANÁLISE E DISCUSSÃO DOS RESULTADOS}

Considerando que as definições das características qualitativas da informação, embora já viessem sendo discutidas há muito, como por exemplo as discussões levantadas por Hendriksen e Van Breda (1999), ficaram claramente definidas na contabilidade brasileira a partir de 2008 , buscou-se verificar, junto aos respondentes, o tempo em que os mesmos estão no curso de ciências contábeis, tendo em vista que, aqueles que ingressaram no curso e frequentaram as disciplinas da linha de contabilidade geral antes de 2008, poderiam apresentar dificuldades no entendimento das características qualitativas da informação contábil.

Tabela 1 - Tempo que está cursando Ciências Contábeis

\begin{tabular}{lccc}
\hline & Frequência & $\mathbf{\%}$ & $\begin{array}{c}\mathbf{\%} \\
\text { Acumulado }\end{array}$ \\
\hline 9 períodos & 30 & 75 & 75 \\
\hline De 10 a 12 períodos & 10 & 25 & 100 \\
\hline De 13 e 14 períodos & 0 & 0 & 100 \\
\hline Total & $\mathbf{4 0}$ & $\mathbf{1 0 0}$ & \\
\hline
\end{tabular}

Fonte: Pesquisa de Campo, 2013.

Na tabela 1 é evidenciado que a maioria dos respondentes estão integralizando toda a estrutura curricular dentro do tempo mínimo estabelecido pelo Projeto Pedagógico do Curso, que é de 9 semestres letivos e, portanto, ingressaram na IES objeto dessa investigação no ano de 2008 e dessa forma, toda a estrutura curricular já fora cursada dentro dos padrões contábeis atuais. Os demais estão a um tempo maior devido a reprovação em algumas disciplinas ou transferência voluntária de outras IES.

No que diz respeito a análise da influência que a presença das características qualitativas exercem na decisão dos respondentes, a análise será feita por característica. 
A característica qualitativa fundamental da Relevância foi analisada a partir de uma situação hipotética em que uma empresa Alfa busca o banco Delta procurando uma concessão de crédito, mas no momento em que o banco analisa as demonstrações percebe que seu índice de liquidez não se enquadra nos seus critérios para concessão financiamento. A partir daí, são dadas duas alternativas para o respondente.

A alternativa pretendida a ser escolhida pelo respondente é a que sugere que o banco não deverá conceder o crédito, pois os requisitos para a concessão não foram atendidos. Posteriormente, apresentou-se mais um dado à informação, o de que a empresa possui controladas e que seus demonstrativos apresentados naquele momento não estariam consolidados. Assim, foram apresentadas novamente as mesmas alternativas, só que desta vez, a alternativa pretendida é aquela que expõe que o banco deverá analisar outras informações para a concessão do crédito, uma vez que os valores constantes nesses novos demonstrativos, poderiam trazer impacto significativo à analise, através da consolidação.

Tabela 2 - Relevância

\begin{tabular}{lcccc}
\hline & \multicolumn{2}{c}{ Sem a característica } & \multicolumn{2}{c}{ Com a característica } \\
\cline { 2 - 5 } & Frequência & $\mathbf{\%}$ & Frequência & $\mathbf{\%}$ \\
\hline Alternativa correta & 16 & 40 & 30 & 75 \\
\hline Alternativa errada & 24 & 60 & 10 & 25 \\
\hline Total & $\mathbf{4 0}$ & $\mathbf{1 0 0}$ & $\mathbf{4 0}$ & $\mathbf{1 0 0}$ \\
\hline
\end{tabular}

Fonte: Pesquisa de Campo, 2013.

Como pode ser visualizada através da Tabela 2, a inclusão de mais uma informação ao problema em questão fez com que os respondentes mudassem de postura, ou seja, percebe-se que uma informação que contenha a característica qualitativa da relevância é capaz de fazer a diferença nas decisões.

A característica qualitativa fundamental da representação fidedigna foi avaliada a partir de uma situação em que uma empresa hipotética deseja vender o prédio que serve de sede de sua empresa, e o mesmo encontrava-se avaliado em seu balanço pelo valor diminuto de $\mathrm{R} \$ 200,00$. Deste modo, foram dispostas duas alternativas que dentre elas a alternativa esperada era a de que adquirir este bem não seria uma boa escolha, pois, levando em consideração o seu valor, provavelmente estaria em péssimas condições de uso.

Posteriormente foi inserida uma informação que demonstrava fidedignidade sobre a real situação do prédio, de modo a justificar o valor baixo para o bem devido ao mesmo já se encontrar quase todo depreciado mediante taxa imposta pelo Fisco, mas 
que o mesmo ainda dispõe de vida útil, estando em uma ótima localização e encontrando-se em boas condições de uso, havendo inclusive valorizado. Diante a informação exposta, a alternativa que se pretendia ser escolhida destaca que seria necessário analisar outras informações para avaliar a possibilidade de compra.

Tabela 3 - Representação Fidedigna

\begin{tabular}{lccccc} 
& \multicolumn{2}{c}{ Sem a característica } & \multicolumn{2}{c}{ Com a característica } \\
\cline { 2 - 5 } & Frequência & $\mathbf{\%}$ & Frequência & $\mathbf{\%}$ \\
\hline Alternativa correta & 2 & 5 & 95 & 36 & 90 \\
\hline Alternativa errada & 38 & $\mathbf{1 0 0}$ & $\mathbf{4 0}$ & 10 \\
\hline Total & $\mathbf{4 0}$ & & $\mathbf{1 0 0}$ \\
\hline
\end{tabular}

Fonte: Pesquisa de Campo, 2013.

Como se percebe, através da tabela pode ser visualizado através da Tabela 3, a inclusão de mais uma informação à situação, no que diz respeito a característica qualitativa da Representação Fidedigna, fez com que os respondentes mudassem drasticamente de postura, ou seja, a presença dessa característica qualitativa fez a diferença nas decisões.

Entrando no contexto das características qualitativas de melhoria, a influência da comparabilidade nas decisões foi avaliada por meio de uma situação em que o banco Delta é procurado para concessão de crédito por duas empresas (Alfa e Beta), e ao analisar seus demonstrativos percebe que Alfa vem apresentando uma lucratividade e um índice de liquidez superior ao de Beta, deste modo, duas alternativas foram apresentadas e a esperada seria aquela que propõe que o banco conceda o empréstimo a empresa Alfa, levando em consideração que ela possui uma capacidade maior que Beta para pagamento de suas obrigações.

Posteriormente, é acrescentada à situação mais uma informação esclarecendo que Alfa e Beta tem estoques apurados de diferentes formas e consequentemente seus resultados foram afetados por isso. Logo, a alternativa escolhida deveria ser aquela que propunha que o banco buscasse outro tipo de informações para decidir o modo de concessão de crédito.

Tabela 4 - Comparabilidade

\begin{tabular}{lcccc}
\hline & \multicolumn{2}{c}{ Sem a característica } & \multicolumn{2}{c}{ Com a característica } \\
\cline { 2 - 5 } & Frequência & $\mathbf{\%}$ & Frequência & $\mathbf{\%}$ \\
\hline Alternativa correta & 21 & 52,5 & 31 & 77,5 \\
\hline Alternativa errada & 19 & 47,5 & 9 & 22,5 \\
\hline Total & $\mathbf{4 0}$ & $\mathbf{1 0 0}$ & $\mathbf{4 0}$ & $\mathbf{1 0 0}$ \\
\hline
\end{tabular}

Fonte: Pesquisa de Campo, 2013. 
Como pode ser visualizado na Tabela 4, a inclusão de mais uma informação ao problema em questão, no que diz respeito a característica qualitativa da Comparabilidade, fez com que alguns dos respondentes mudassem de comportamento, mas que na verdade, mesmo sem a informação com a característica em questão, a maioria dos respondentes já haviam tomado a decisão esperada.

A verificabilidade, por sua vez, teve sua influencia na tomada de decisão avaliada através de uma caso em que uma determinada empresa estava sendo auditada e necessita de informações sobre o cálculo da depreciação, para tanto, solicita tais informações de seu contador, onde o mesmo explica que a depreciação é calculada mediante taxa de $10 \%$ ano. A partir dessas informações foi questionado sobre a utilidade da mesma e apresentou-se, assim como nas outras situações, duas alternativas onde a esperada seria aquela que afirma que a informação repassada pelo contador não tem utilidade por serem insuficientes para o entendimento do cálculo da depreciação. Posteriormente acrescentou-se mais informações a respeito do calculo da depreciação, como o método empregado, a vida útil determinada e o valor residual do bem. Assim, após a inclusão de tais informações, esperava-se que a alternativa escolhida fosse aquela que considera a informação como útil, uma vez que havia a necessidade de tais dados para que se pudesse verificar a veracidade das informações divulgadas.

Tabela 5 - Verificabilidade

\begin{tabular}{lcccc}
\hline & \multicolumn{2}{c}{ Sem a característica } & \multicolumn{2}{c}{ Com a característica } \\
\cline { 2 - 5 } & Frequência & $\mathbf{\%}$ & Frequência & $\mathbf{\%}$ \\
\hline Alternativa correta & 9 & 22,5 & 33 & 82,5 \\
\hline Alternativa errada & 31 & 77,5 & 7 & 17,5 \\
\hline Total & $\mathbf{4 0}$ & $\mathbf{1 0 0}$ & $\mathbf{4 0}$ & $\mathbf{1 0 0}$ \\
\hline
\end{tabular}

Fonte: Pesquisa de Campo, 2013.

Logo, como encontra-se evidenciado na tabela 5, a inclusão de mais uma informação ao problema em questão, no que diz respeito a característica qualitativa da Verificabilidade, fez com que os respondentes mudassem drasticamente de postura, ou seja, a presença dessa característica qualitativa faz a diferença nas decisões.

A utilidade da tempestividade foi avaliada através de uma situação em que um empresário tinha o interesse de investir no mercado de ações, e para tanto, fez uma análise das demonstrações da empresa que desejava investir, exceto nas notas explicativas, e diante da análise, constatou que as ações estavam sempre em alta e apresentava uma crescente lucratividade ao longo dos anos, decidindo investir grande 
parte de seu capital. Diante das duas alternativas propostas, esperava-se que a escolhida fosse aquela que o investidor tinha tomado a decisão correta, porque analisou os demonstrativos da investida e viu nestes expectativas de rentabilidade.

Posteriormente acrescentou-se a informação de que dias depois da análise feita pelo investidor foi divulgada o parecer de auditoria adverso, afirmando que os demonstrativos da empresa em questão foram manipulados de tal forma que indícios de falência foram "maquiados". Desta forma, sabe-se que se essa informação tivesse chegado ao investidor no momento oportuno/tempestivo, a decisão do mesmo seria outra cometido. Mediante tais informações, a alternativa escolhida que se esperava dos respondentes era aquela que recomendava ao investidor mais cautela no sentido de, mesmo sabendo que a empresa estava em alta no mercado, aguardar mais informações para tomada de decisão, uma vez que ele não teve acesso a todas as informações necessárias para a tomada de tal decisão e que aquela informação divulgada, para a decisão em tela, era inútil.

Tabela 6 - Tempestividade

\begin{tabular}{lccccc}
\hline & \multicolumn{2}{c}{ Sem a característica } & \multicolumn{2}{c}{ Com a característica } \\
\cline { 2 - 5 } & Frequência & $\mathbf{\%}$ & Frequência & $\mathbf{\%}$ \\
\hline Alternativa correta & 8 & 20 & 33 & 82,5 \\
\hline Alternativa errada & 32 & 80 & 7 & 17,5 \\
\hline Total & $\mathbf{4 0}$ & $\mathbf{1 0 0}$ & $\mathbf{4 0}$ & $\mathbf{1 0 0}$ \\
\hline
\end{tabular}

Fonte: Pesquisa de Campo, 2013.

Na tabela 7 fica evidenciado que inclusão de mais uma informação ao problema em questão, no que diz respeito a característica qualitativa da Tempestividade, fez com que os respondentes mudassem drasticamente de postura, ou seja, se aquela informação fosse tempestiva a decisão teria sido outra.

Por fim, a característica qualitativa de melhoria da compreensibilidade teve impacto avaliado através da situação hipotética em que um investidor, que acaba de entrar no mercado de ações e com pouca experiência, busca investir em uma empresa integrante de um grupo econômico, e ao fazer uma análise em seus demonstrativos consolidados encontram-se ativos reconhecidos como Goodwill, e com uma série de dúvidas sobre o assunto procura um contador que tenta lhe esclarecer tal dúvida explicando, que uma das causas para a existência de um Goodwill elevado deve-se a existência de off balance sheets assets. Diante da situação exposta, foram apresentadas duas alternativas, dentre as quais a esperada seria aquela que a informação fornecida pelo contador não teria utilidade uma vez que devido ao fato do investidor não possuir 
conhecimento técnico sobre tal assunto, mesmo que o contador tenha explicado, ele precisa estudar o assunto com diligência para conhecimento da situação.

$\mathrm{Na}$ outra situação hipotética correspondente a característica da compreensibilidade, como explicação para existência do Goodwill elevado, o contador explica que isso se deve à existência de ativos que, mesmo atendendo a definição de ativos, não atendiam aos critérios de reconhecimento por não possuírem, nos balanços individuais das controladas, medida confiável, incorrendo em diferenças significativas entre o valor patrimonial da empresa e seu valor de mercado e que só na aquisição de negócios que se identifica essa diferença. Desta forma, tal informação pôde se tornar compreensível, de modo que após essa explicação, os respondentes deveriam optar pela alternativa que afirma que com a explicação do contador, mesmo que o investidor tivesse pouco entendimento, teria entendido o ocorrido, tornando a informação útil àquela decisão.

Tabela 7 - Compreensibilidade

\begin{tabular}{lccccc}
\hline & \multicolumn{2}{c}{ Sem a característica } & \multicolumn{2}{c}{ Com a característica } \\
\cline { 2 - 5 } & Frequência & $\mathbf{\%}$ & Frequência & $\mathbf{\%}$ \\
\hline Alternativa correta & 10 & 25 & 22 & 55 \\
\hline Alternativa errada & 30 & 75 & 18 & 45 \\
\hline Total & $\mathbf{4 0}$ & $\mathbf{1 0 0}$ & $\mathbf{4 0}$ & $\mathbf{1 0 0}$ \\
\hline
\end{tabular}

Fonte: Pesquisa de Campo, 2013.

Como está evidenciado através da Tabela 7, a inclusão de uma informação compreensível, fez com que alguns dos respondentes mudassem de postura em direção à resposta pretendida, ou seja, a presença dessa característica qualitativa faz a diferença nas decisões.

A Tabela 8 resume as respostas dos concludentes quanto ao grau de importância atribuído a cada característica qualitativa da informação contábil. Assim, é possível elaborar um ranking dentre as características qualitativas destacando apenas o mais alto grau de importância elencado (muito importante). 
Tabela 8 - Resumo do Grau de Importância das Características Qualitativas

\begin{tabular}{lcccccc}
\hline $\begin{array}{c}\text { Grau de } \\
\text { importância }\end{array}$ & $\begin{array}{c}\text { Relev. } \\
\mathbf{\%}\end{array}$ & $\begin{array}{c}\text { Rep. Fid. } \\
\mathbf{\%}\end{array}$ & $\begin{array}{c}\text { Compa. } \\
\mathbf{\%}\end{array}$ & $\begin{array}{c}\text { Verif. } \\
\mathbf{\%}\end{array}$ & $\begin{array}{c}\text { Temp. } \\
\mathbf{\%}\end{array}$ & $\begin{array}{c}\text { Compreen. } \\
\mathbf{\%}\end{array}$ \\
\hline Sem importância & 2,5 & 0 & 0 & 0 & 2,5 & 0 \\
\hline Pouco importante & 0 & 5 & 2,5 & 0 & 0 & 5 \\
\hline Neutro & 10 & 10 & 27,5 & 15 & 10 & 10 \\
\hline Importante & 27,5 & 32,5 & 32,5 & 27,5 & 37,5 & 32,5 \\
\hline Muito importante & 60 & 52,5 & 37,5 & 57,5 & 50 & 52,5 \\
\hline Total & $\mathbf{1 0 0}$ & $\mathbf{1 0 0}$ & $\mathbf{1 0 0}$ & $\mathbf{1 0 0}$ & $\mathbf{1 0 0}$ & $\mathbf{1 0 0}$ \\
\hline
\end{tabular}

Fonte: Pesquisa de Campo, 2013.

A característica Relevância ocupou o primeiro lugar, sendo considerado muito importante, seguida pela Verificabilidade, Representação Fidedigna, Compreensibilidade, Tempestividade e por fim a Comparabilidade.

Após análise do grau de importância das características qualitativas (Tabela 81), pode-se comprovar que o resultado da Tabela 4 que trata da Comparabilidade pode ter sido influenciado pelo fato dos respondentes julgarem tal característica como a de menor importância dentre todas as outras, de forma que esta não teve tanta influência na escolha da alternativa que continha a característica.

Por meio de uma análise dos dados observa-se que todas as características foram consideradas como importantes ou muito importantes pela maioria dos pesquisados. Apenas um dos respondentes julgou a Relevância e a Tempestividade como sem importância, para tanto, foi feita uma análise individual do questionário desse respondente, onde pôde ser constatado que o mesmo não obteve um desempenho satisfatório diante dos resultados esperados dentro na pesquisa, tal acontecimento pode ser justificado como insuficiência de domínio e compreensão do tema abordado ou desinteresse de resolução do questionário.

Fazendo uma análise sobre o resultado das questões constantes nos grupos 3 e 4, nota-se que a característica que mais gerou impacto na tomada de decisão foi a Representação Fidedigna contemplando 90\% das alternativas pretendidas, em seguida temos a Tempestividade e Verificabilidade com 82,5\%, Comparabilidade com 77,5\%, Relevância com $75 \%$, e por fim a Compreensibilidade com $55 \%$. 


\section{CONSIDERAÇÕES FINAIS}

A contabilidade tem como finalidade o fornecimento de informações úteis, para que os seus vários usuários possam subsidiar o processo de tomada de decisão. Para tanto, a informação contábil precisa estar dotada de certas características qualitativas, de modo que, o entendimento do usuário sobre o assunto e a forma como a informação é apresentada determinam a utilidade da mesma diante os diversos modelos decisórios que cada usuário pode ter.

O presente trabalho, realizado por meio de pesquisa com os alunos concludentes do curso de ciências contábeis da UFCG do campus de Sousa, buscou verificar se a presença das características qualitativas das informações contábeis exerce impacto no processo decisório e, para tanto, buscou-se avaliar a percepção dos concludentes acerca do seu conhecimento relacionado às características qualitativas da informação contábil e sua importância no processo de comunicação; verificar o grau de importância atribuído pelos concludentes a cada uma das características abordadas na pesquisa; e comparar o grau de importância atribuído às características qualitativas e o impacto que a presença dessas características tiveram nas decisões propostas.

As conclusões são fundamentadas nos resultados adquiridos com base no instrumento de coleta de dados adotado.

Ao se fazer um comparativo entre as perguntas que compõem o questionário, pôde-se perceber que a forma como tais informações são apresentadas e as presenças das características qualitativas da informação contábil exerceram um impacto na tomada de decisão.

Quanto ao grau de importância atribuído pelos respondentes a cada característica qualitativa da informação contábil, observou-se que em sua maioria foram consideradas como importantes ou muito importantes, com exceção de um respondente que julgou a Relevância e a Tempestividade como sem importância. Para tanto, foi feita uma análise individual deste questionário, e constatou-se que o mesmo não apresentou um desempenho satisfatório na resolução do questionário, se comparado às decisões esperadas, diante das situações expostas aos respondentes.

Por conseguinte, ao se fazer um comparativo entre o grau de importância de tais características qualitativas com o impacto de sua presença para a tomada de decisão, foi possível perceber que aquelas que foram julgadas como importantes e muito importantes em sua maioria, influenciaram na tomada de decisão.

Assim, como perspectiva para trabalhos futuros, recomenda-se a aplicação do questionário em outras instituições de ensino superior, além de avaliar por meio de 
testes estatísticos específicos, se as diferenças apresentadas antes e após a inclusão de informações úteis podem ser consideradas como estatisticamente significativas.

\section{REFERÊNCIAS}

ALVES, M. do C. G. Relevância da informação contabilística: abordagem teórica e estudo empírico. 2003. Disponível em: <http://www.ti.usc.es/lugo-xiii-hispano-lusas>. Acessado em: 05 mar. 2013.

BERLO, D. K. O processo de comunicação: Introdução à teoria e prática. Trad. Jorge Arnaldo Fontes. Revisão Técnica: Irami B. Silva. 8. Ed., São Paulo: Martins Fontes, 1997. CARVALHO, L. N. Contabilidade \& ecologia: Uma exigência que se impõe. Revista Brasileira de Contabilidade. n. 75, p. 20-25, abril/julho 1991.

COMITE DE PRONUNCIAMENTOS CONTÁBEIS. Pronunciamento Conceitual Básico. Estrutura Conceitual para a Elaboração e Apresentação das Demonstrações Contábeis. Brasília, 2008. Disponível em <http://cfc.org.br/uparq/livro_CPC2.pdf>, acessado em: 20/12/2012.

- Pronunciamento Conceitual Básico. Estrutura Conceitual para a Elaboração e Apresentação das Demonstrações Contábeis. Brasília, 2011. Disponível em < http://www.cpc.org.br/pdf/cpc00_r1.pdf>, acessado em: 20/12/2012.

CONSELHO FEDERAL DE CONTABILIDADE. Resolução N 774, de 16 de dezembro de 1994. Aprova o apêndice à resolução sobre os princípios fundamentais de contabilidade. Princípios fundamentais de contabilidade e normas brasileiras de contabilidade. Brasília: CFC, $1999 . \quad$ Disponível em: <http://www.senar.org.br/legislacao/setor_cont/res_cfc_774.pdf>, acesso em: 12/03/2013.

DIAS, C. B. P. et al. Ruídos na comunicação entre a contabilidade e os seus usuários. In: Congresso USP de Controladoria e Contabilidade, 2004, São Paulo. Disponível em $<$ http://www.congressousp.fipecafi.org/artigos42004/160.pdf>, acesso em: 22/12/2012.

DIAS FILHO, J. M. NAKAGAWA, M. Análise do Processo da Comunicação Contábil: Uma Contribuição para a Solução de Problemas Semânticos, Utilizando Conceitos da Teoria da Comunicação. Revista Contabilidade \& Finanças FIPECAFI - FEA - USP. São 
Paulo, v. 15, n. 26, p. 42 - 57, maio/agosto 2001. Disponível em: <http://www.scielo.br/pdf/rcf/v12n26/v12n26a03.pdf>, acesso em: 13/03/2013.

DIAS FILHO, J M. A linguagem utilizada na informação contábil: uma análise de sua compreensibilidade à luz da Teoria da Comunicação. Caderno de Estudos FIPECAFI, v. 13, n. 24, p. 38-49, São Paulo: julho - dezembro 2000. Disponível em <http://www.scielo.br/scielo.php?pid=S1413-92512000000200003\&script=sci_arttext>, acesso em 16/01/2013.

FEA/USP. Contabilidade introdutória. Sérgio Iudícibus (Coord.). 10 ed. São Paulo: Atlas, 2006.

FUJINO, A. ; Valente. N. T. V. .Características qualitativas da informação contábil e os atributos e dimensões de qualidade na Ciência da informação. In: VI Congresso ANPCONT, 2012, Florianópolis. Contabilidade e Desenvolvimento Organizacional Frente Às Dinâmicas Sociais. florianopolis : ANPCONT, 2012. Disponível em? $<$ https://uspdigital.usp.br/tycho/producaoacademica/eca/cbd/P4-0.html > , acessado em 03/02/2012.

GOUVEIA, F. H. C. Uma incursão pela abordagem de pesquisa em contabilidade no Brasil fundamentada em teorias semióticas e da comunicação. São Paulo, 2010. Disponível em <http://www.teses.usp.br/teses/disponiveis/12/12136/tde-30112010161305/pt-br.php>, acesso em 16/01/2013.

HENDRIKSEN, E. S.; VAN BREDA, M. F. (1999). Teoria da Contabilidade. São Paulo, Editora Atlas, 5ª Edição. Holt, Rinehartand Winston, 1960.

IASB. International Accounting Standards Board. Estrutura conceitual para a elaboração e apresentação das demonstrações contábeis. Normas Internacionais de Contabilidade. São Paulo: IBRACON, 2001.

IUDICIBUS, S. de .Teoria da Contabilidade. 9. Ed. São Paulo: Atlas, 2009.

LIBONATI, J. J.; SOUTO MAIOR, V. C. O papel da comunicação na contabilidade. In: CONGRESSO BRASILEIRO DE CONTABILIDADE. 15, 1996, Fortaleza. Anais. Brasília: Conselho Federal de Contabilidade, 1996. V. 4. P. 230-254. 
OLIVEIRA, F. D. C. de; et al. Características Qualitativas da Informação...

PAIVA, P. R. Contabilidade Ambiental: Evidenciação dos Gastos Ambientais com Transparência e Focada na Prevenção. São Paulo: Atlas, 2009. 